\title{
Corrosion and Electrochemical Properties of Nanocrystalline W-Mo Alloys in $\mathrm{NaOH}$ Solutions
}

\author{
Arun Khadka and Jagadeesh Bhattarai \\ Central Department of Chemistry, Tribhuvan University, Kirtipur, Kathmandu \\ e-mail:bhattarai_05@yahoo.com
}

\begin{abstract}
The corrosion and electrochemical properties of sputter-deposited nanocrystalline binary W-Mo alloys were studied after immersion for $2429 \mathrm{~h}$ in different concentrations of $\mathrm{NaOH}$ solutions open to air at $25^{\circ} \mathrm{C}$ using corrosion tests and open circuit potential measurements. Molybdenum acts synergistically with tungsten in enhancing the corrosion resistance of the sputter-deposited binary W-Mo alloys so as to show higher corrosion resistance than those of alloy-constituting elements (i.e. tungsten and molybdenum) after immersion for $24 \mathrm{~h}$ in $\mathrm{NaOH}$ solutions. Open circuit potentials of all the examined sputter-deposited W-Mo alloys are shifted to the more positive (noble) direction with increasing molybdenum content in the alloys. The stability of the spontaneously passivated films formed on the binary W-Mo alloys is decreased with increasing concentrations of $\mathrm{NaOH}$ solutions. In spite of these facts, the corrosion rates of all the examined $\mathrm{W}-\mathrm{Mo}$ alloys are almost independent of concentrations of $\mathrm{NaOH}$ solutions after immersion for $24 \mathrm{~h}$ at $25^{\circ} \mathrm{C}$.
\end{abstract}

Key words: nanocrystalline W-Mo alloys, sputter deposition, corrosion resistance, open circuit potential, $\mathrm{NaOH}$ solutions

\section{Introduction}

The development of new corrosion resistance engineering materials is provoked by different reasons and one of them is the improved corrosion resistance properties of the materials. The research activities on the sputter-deposited amorphous or/and nanocrystalline binary or ternary alloys are recently being of a widespread interest in the field of corrosion science and engineering. The sputter deposition technique is generally used as one of the potential techniques for the preparation of varieties of corrosionresistant amorphous or/and nanocrystalline alloys (Zarzycki 1991). It has been reported that the sputterdeposited amorphous or/and nanocrystalline alloys are chemically more homogeneous structures than conventionally processed crystalline alloys (Heusler et al. 1988, Hashimoto 1993), and hence such sputterdeposited alloys are interesting for high corrosion resistance properties. A variety of extremely high corrosion resistance sputter-deposited singlephase amorphous or/and nanocrystalline chromium (Kim et al. 1993, 1994; Li et al. 1997)- molybdenum (Park et al. 1994, 1995, 1996; Hashimoto 2007), tungsten (Bhattarai 1995, 1998, 2000, 2001, 2002, 2006, 2009; Bhattarai \& Hashimoto 1998; Bhattarai et al. 1995, 1997, 1998 a, 1998 b, 1998 c, 2000)- and manganese (ElMoneim et al. 1997, 1999)- transition metal alloys have been developed for last two decades.

In 1990s Park et al. (1994, 1995, 1996), and Bhattarai (1995, 1998, 2009) and Bhattarai et al. (1995, 1997, 1998 a, 1998 b, 1998 c, 1999) had reported the synergistic effect of molybdenum addition on the sputterdeposited binary amorphous and/or nanocrystalline molybdenum- and tungsten-transition metals (nickel, chromium, zirconium, niobium, tantalum, molybdenum) alloys, respectively, for significantly high corrosion resistance properties in $12 \mathrm{M} \mathrm{HCl}$ solutions open to air at $30^{\circ} \mathrm{C}$. It has also been found that the addition of 
molybdenum improved the passivating ability of the sputter-deposited ternary Al-Cr-Mo alloys not by formation of molybdenum enriched passive film, but by the formation of chromium enriched passive film ( Akiyama et al. 1996). In particular, the sputterdeposited nanocrystalline W-Mo alloys containing about 24-83 at \% molybdenum were spontaneously passivated and showed high corrosion resistance than those of alloy-constituting elements in both $12 \mathrm{M} \mathrm{HCl}$ (Bhattarai 2006) and $0.5 \mathrm{M} \mathrm{NaCl}$ solutions (Bhattarai et al. 2010). It is meaningful for mentioning here that tungsten is passive in the acidic environments having $\mathrm{pH}<4$, whereas it corrodes in alkaline and neutral solutions from potential-pH diagram (Pourbaix 1974). On the other hand, molybdenum is passive only in a very narrow potential values at $\mathrm{pH} 4-8$ of the environments and corrodes in both acidic and alkaline solutions (Pourbaix 1974). Considering these facts, present work is focused to study the effect of molybdenum on the corrosion behavior of the binary nanocrystalline $\mathrm{W}-\mathrm{Mo}$ alloys in different concentrations of $\mathrm{NaOH}$ solutions open to air at $25^{\circ} \mathrm{C}$ using corrosion tests and electrochemical measurements.

\section{Methodology}

The binary W-Mo alloys were prepared by direct current (D. C.) magnetron sputtering on glass substrate as described elsewhere (Bhattarai 1995, 2006 Bhattarai et al. 2010). An electron probe microanalysis was used to determine the compositions of the sputter-deposited alloys. The sputter-deposited binary W-Mo alloys were confirmed as a nanocrystalline single phase solid solution by $\mathrm{X}$-ray diffraction having the apparent grain size ranging from 15.0 to $19.8 \mathrm{~nm}$ (Bhattarai 1995, 2006; Bhattarai et al. 2010).

Prior to immersion tests and open circuit potential measurements, the nanocrystalline W-Mo alloy specimens were mechanically polished with a silicon carbide paper up to grit number 1500 in cyclohexane, rinsed by acetone and dried in air. The average corrosion rate of the alloys was estimated from the weight loss after immersion for about $24 \mathrm{~h}$ in $1 \mathrm{M} \mathrm{NaOH}$ solution open to air at $25^{\circ} \mathrm{C}$. The average corrosion rate measurement was done two times or more so as to get precise results. The time dependence of the corrosion rate was also estimated after immersion for
2-29 h in $0.01 \mathrm{M}, 0.1 \mathrm{M}$ and $1 \mathrm{M} \mathrm{NaOH}$ solutions. The open circuit potential of all the examined W-Mo alloys was measured after immersion for $2 \mathrm{~h}$ in $1 \mathrm{M} \mathrm{NaOH}$ solution open to air at $25^{\circ} \mathrm{C}$. Alloys and saturated calomel electrode were used as working and reference electrodes, respectively. All the potentials given in this paper are relative to saturated calomel electrode (SCE).

\section{Results and Discussion}

Figure 1 shows changes in the average corrosion rates of the sputter-deposited nanocrystalline W-Mo alloys including tungsten and molybdenum after immersion for $24 \mathrm{~h}$ in $1 \mathrm{M} \mathrm{NaOH}$ solution open to air at $25^{\circ} \mathrm{C}$, as a function of alloy molybdenum content. The corrosion rates of the sputter-deposited tungsten and molybdenum are about $5.25 \times 10^{-1} \mathrm{~mm} \cdot \mathrm{y}^{-1}$ and $1.04 \times$ $10^{-1} \mathrm{~mm} . \mathrm{y}^{-1}$, respectively. The corrosion rates of the sputterdeposited binary W-Mo alloys containing 2483 at \% molybdenum show about one order of magnitude lower corrosion rates than that of tungsten and even lower corrosion rates than that of the sputter-deposited molybdenum metal in $1 \mathrm{M} \mathrm{NaOH}$ solution at $25^{\circ} \mathrm{C}$. In particular, the sputter-deposited W-Mo alloys containing 24-52 at \% molybdenum show lowest corrosion rates (i.e., about $4.5 \times 10^{-2}$ mm. $\mathrm{y}^{-1}$ ) among all the examined $\mathrm{W}-\mathrm{Mo}$ alloys than those of alloy-constituting elements (i.e. tungsten and molybdenum) after immersion for $24 \mathrm{~h}$ in an aggressive $1 \mathrm{M} \mathrm{NaOH}$ solution at $25^{\circ} \mathrm{C}$. These results revealed that the synergistic effects of the simultaneous

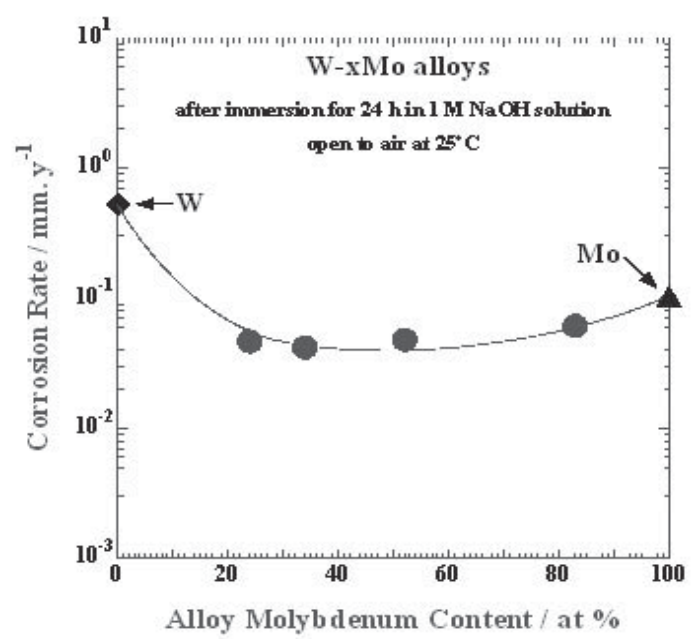

Fig. 1. Changes in corrosion rates of the sputter-deposited nanocrystalline $\mathrm{W}-\mathrm{xMo}$ alloys including tungsten and molybdenum metals in $1 \mathrm{M} \mathrm{NaOH}$ solution open to air at $25^{\circ} \mathrm{C}$, as a function of alloy molybdenum content 
additions of tungsten and molybdenum metals to the sputter-deposited nanocrystalline W-Mo alloys is clearly observed in $1 \mathrm{M} \mathrm{NaOH}$ solution. It is meaningful for mentioning here that the corrosion resistance of these alloys in $12 \mathrm{M} \mathrm{HCl}\left(1-2 \times 10^{-3} \mathrm{~mm}\right.$. $y^{-}$ ${ }^{1}$ corrosion rates) (Bhattarai 1995, 2006) and $0.5 \mathrm{M} \mathrm{NaCl}$ (1.7-2.0 $\times 10^{-2} \mathrm{~mm} . \mathrm{y}^{-1}$ corrosion rates) (Bhattarai et al.
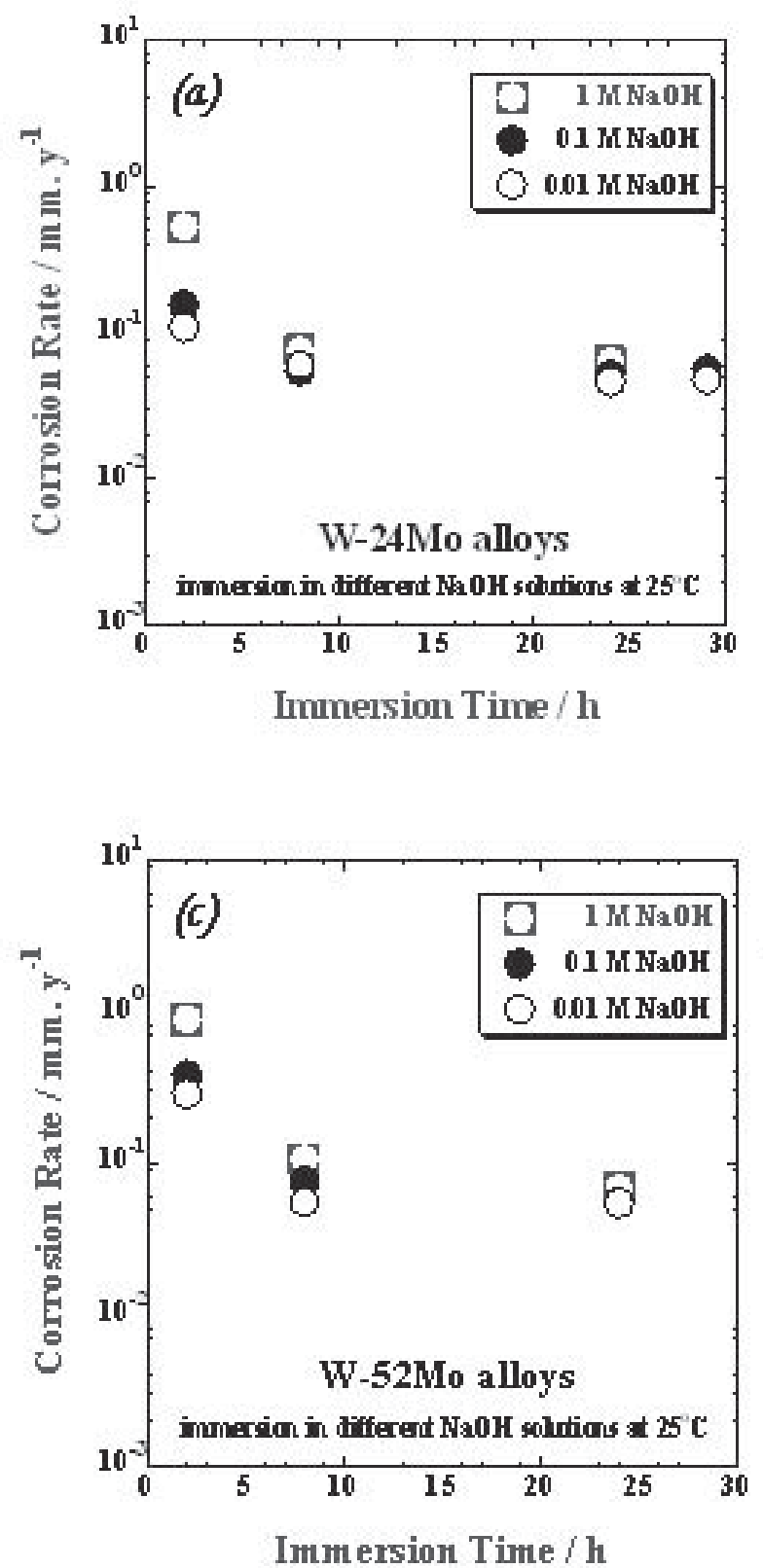

2010) solutions were reported lower than in $1 \mathrm{M} \mathrm{NaOH}$ solution presented in this work. These results revealed that the general corrosion rates of the sputterdeposited W-Mo alloys showed lowest corrosion resistance in alkaline environment than those in neutral and acidic environments.
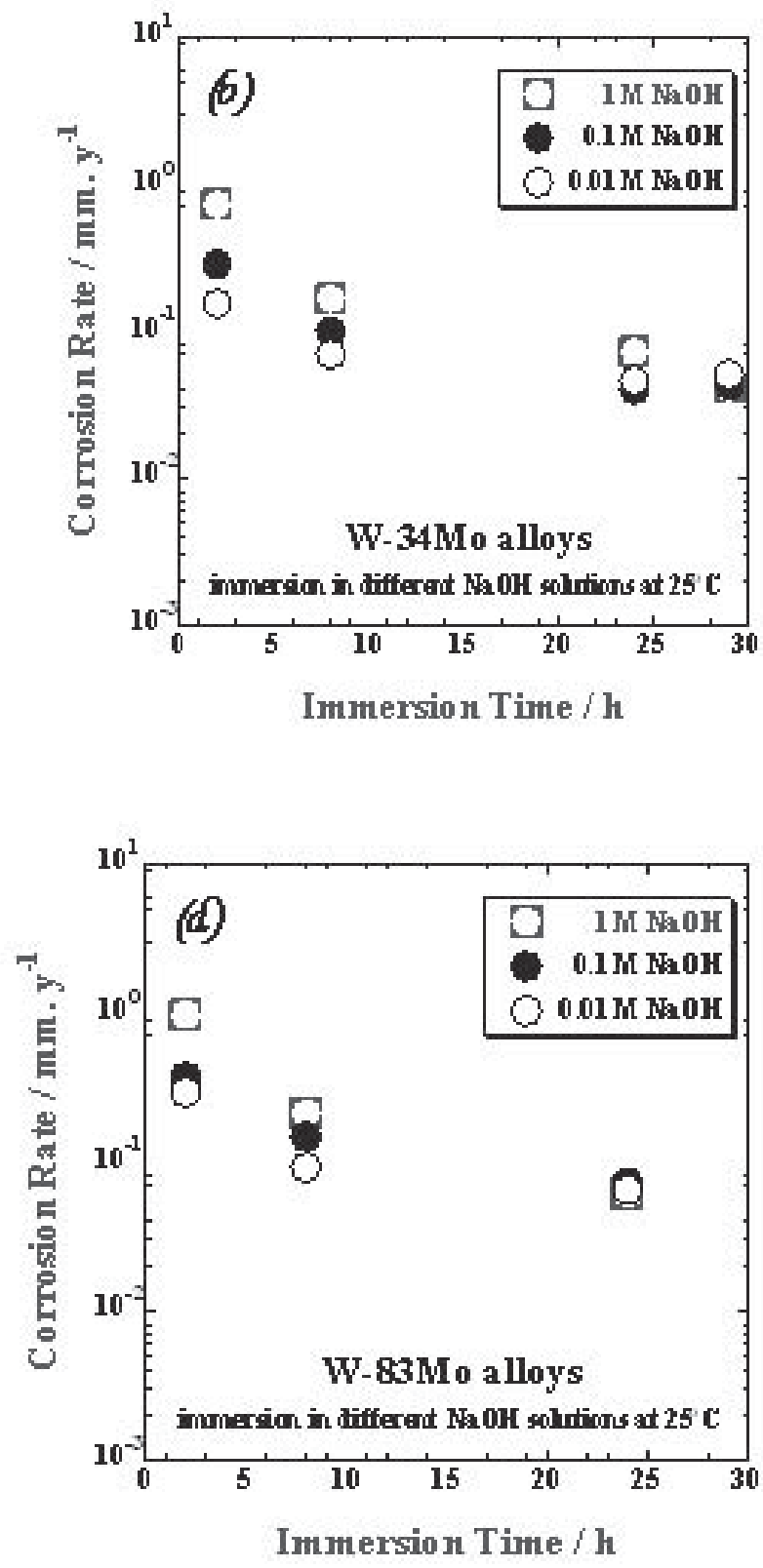

Fig. 2. The change in corrosion rate of the sputter-deposited nanocrystalline (a) W-24Mo, (b) W-34Mo, (c) W-52Mo and (d) W-83Mo alloys in $0.01 \mathrm{M}, 0.1 \mathrm{M}$ and $1 \mathrm{M} \mathrm{NaOH}$ solutions open to air at $25^{\circ} \mathrm{C}$, as a function of immersion time 
Furthermore, the average corrosion rates of all the examined $\mathrm{W}-\mathrm{Mo}$ alloys in $0.01 \mathrm{M}$ and $0.1 \mathrm{M} \mathrm{NaOH}$ solutions were found to be almost same as that in $1 \mathrm{M}$ $\mathrm{NaOH}$ solution after immersion for about $24 \mathrm{~h}$ at $25^{\circ} \mathrm{C}$. Therefore, it is important to identify the role of immersion time for better understanding of the corrosion nature of the alloys. In order to clarify the time dependence of corrosion rates of the sputterdeposited nanocrystalline $\mathrm{W}-\mathrm{xMo}$ alloys, corrosion rates of $\mathrm{W}-24 \mathrm{Mo}, \mathrm{W}-34 \mathrm{Mo}, \mathrm{W}-52 \mathrm{Mo}$ and $\mathrm{W}-83 \mathrm{Mo}$ alloys were estimated after immersion in $0.01 \mathrm{M}, 0.1 \mathrm{M}$ and $1 \mathrm{M} \mathrm{NaOH}$ solutions at various time intervals. Figure 2 shows the changes in the corrosion rates of W-xMo alloys in $0.01 \mathrm{M}, 0.1 \mathrm{M}$ and $1 \mathrm{M} \mathrm{NaOH}$ solutions open to air at $25^{\circ} \mathrm{C}$, as a function of immersion time. In general, the corrosion rates of all the examined W-xMo alloys were significantly high at initial period of immersion (i.e. for 2 h). The corrosion rate was decreased with immersion time till about $8 \mathrm{~h}$ for $\mathrm{W}-$ xMo alloys containing 24-83 atomic \% molybdenum and the corrosion rates of all the examined sputterdeposited nanocrystalline W-Mo alloys became almost steady after immersion for about $24 \mathrm{~h}$. In particular, the corrosion rates of the alloys were remarkably higher in $1 \mathrm{M} \mathrm{NaOH}$ solution than in $0.01 \mathrm{M}$ and $0.1 \mathrm{M} \mathrm{NaOH}$ solutions after immersion for about 8 $\mathrm{h}$ or short times. However, the corrosion rates of the $\mathrm{W}-\mathrm{xMo}$ alloys were almost same in all three different concentrations of $\mathrm{NaOH}$ solutions after immersion for 8-29 h. Accordingly, initially fast dissolution of the $\mathrm{W}-\mathrm{Mo}$ alloys resulted in fast passivation by forming more protective passive films formed on the alloys in $1 \mathrm{M} \mathrm{NaOH}$ solution open to air at $25^{\circ} \mathrm{C}$. Consequently, the average corrosion resistance of the sputterdeposited binary W-Mo alloys containing 24-83\% molybdenum was higher than those of pure tungsten as well as molybdenum after immersion for about $24 \mathrm{~h}$ as shown in figure 1.

Electrochemical measurements were carried out for a better understanding of the corrosion behavior of the sputter-deposited nanocrystalline W-Mo alloys for about $2 \mathrm{~h}$ in alkaline $0.01 \mathrm{M}, 0.1 \mathrm{M}$ and $1 \mathrm{M} \mathrm{NaOH}$ solutions open to air at $25^{\circ} \mathrm{C}$. Figures 3 (a), 3 (b) and 3(c) showed the changes in open circuit potentials for the sputter-deposited nanocrystalline W-Mo alloys as well as the tungsten metal in $1 \mathrm{M}, 0.1 \mathrm{M}$ and $0.01 \mathrm{M}$ $\mathrm{NaOH}$ solutions, respectively, as a function of immersion time. The open circuit potentials of the sputter-deposited nanocrystalline W-Mo alloys were in more noble (positive) direction with increasing the molybdenum content particularly in $1 \mathrm{M} \mathrm{NaOH}$ solution as shown in Fig. 3 (a).
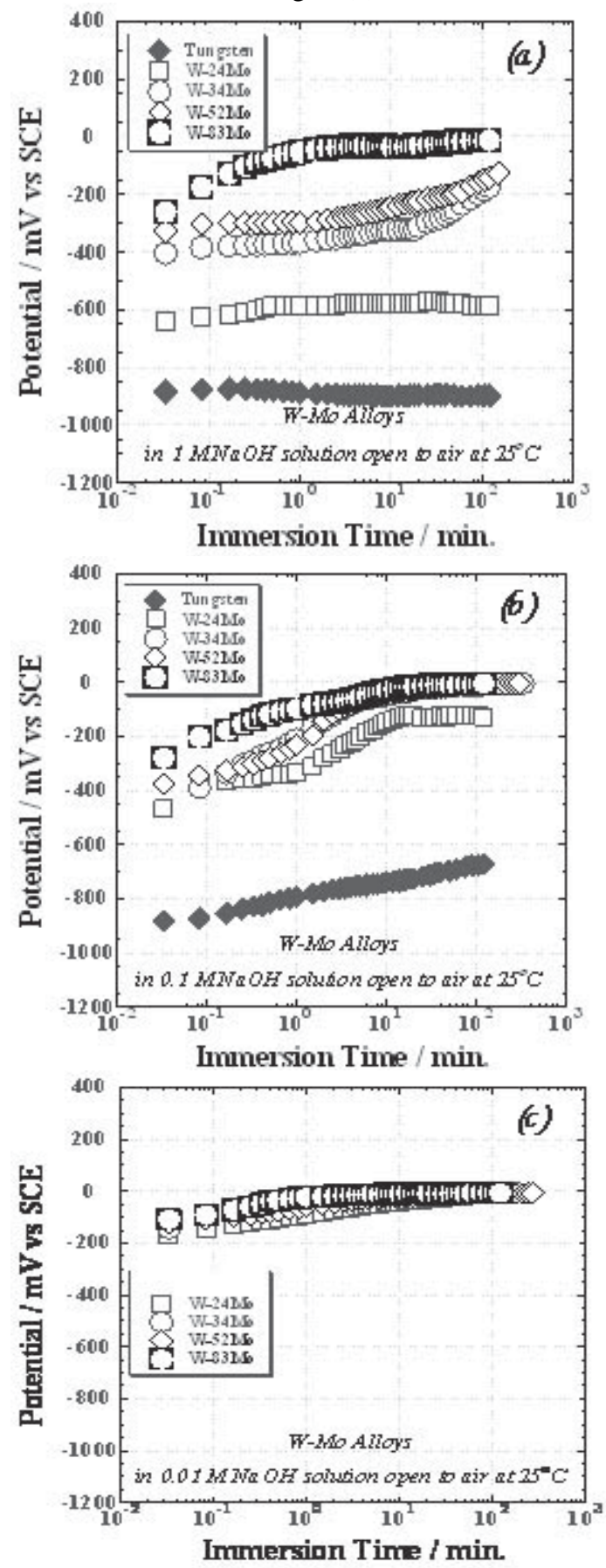

Fig. 3. Changes in open circuit potentials for the sputterdeposited nanocrystalline W-Mo alloys including tungsten metals in (a) $1 \mathrm{M}$, (b) $0.1 \mathrm{M}$ and (c) $0.01 \mathrm{M} \mathrm{NaOH}$ solutions open to air at $25^{\circ} \mathrm{C}$, as a function of immersion time 
Furthermore, the open circuit potentials of all the examined W-Mo alloys were increased with immersion time and attained a steady state after immersion for about 10 min in different concentrations of $\mathrm{NaOH}$ solutions. In particular, the open circuit potentials of all the W-Mo alloys containing $24-83$ at \% molybdenum were almost same in $0.01 \mathrm{M} \mathrm{NaOH}$ solution. These facts coincide with the changes in the corrosion rates of the sputter-deposited nanocrystalline $\mathrm{W}-$ Mo alloys after immersion for $2 \mathrm{~h}$ in different concentrations of $\mathrm{NaOH}$ solutions as shown in Fig. 2.

From the above results and discussion we have drawn these conclusions from our present study. Corrosion rates of all the examined sputter-deposited nanocrystalline $\mathrm{W}-\mathrm{Mo}$ alloys showed about one order of magnitude lower corrosion rates ( that is, $4-5 \times 10^{-2}$ mm. $\mathrm{y}^{-1}$ ) than that of sputter-deposited tungsten and even lower corrosion rate than that of the sputterdeposited molybdenum after immersion for $24 \mathrm{~h}$ in $\mathrm{NaOH}$ solutions. The corrosion rates of the $\mathrm{W}-\mathrm{Mo}$ alloys were almost independent of $\mathrm{NaOH}$ concentrations at $25^{\circ} \mathrm{C}$. Open circuit potentials of the $\mathrm{W}$-Mo alloys are shifted to the noble (more positive) direction with increasing molybdenum content in $\mathrm{NaOH}$ solutions. The stability of the spontaneously passivated films formed on the binary tungsten-rich W-Mo alloys is increased with decreasing $\mathrm{NaOH}$ concentrations, although such effect is not observed for the molybdenum-rich W-Mo alloys after immersion for two hours in $\mathrm{NaOH}$ solutions.

\section{Acknowledgements}

Authors are thankful to the Central Department of Chemistry, Tribhuvan University, Kathmandu, Nepal for providing us the research facilities to conduct this work.

\section{References}

Akiyama, E., H. Habazaki, A. Kawashima, K. Asami and K. Hashimoto. 1996. The corrosion behavior of sputter-deposited amorphous Al-Cr-Mo alloys in 1 M HCl. Corrosion Science 38:279-292, 1281-1294.

Bhattarai, J. 1995. Corrosion behavior of sputter-deposited tungsten-base alloys. Research Reports, Institute for
Materials Research (IMR), Tohoku University, Sendai, Japan, pp. 43+IV.

Bhattarai, J. 1998. Tailoring of corrosion resistance tungsten alloys by sputtering. Ph. D. thesis, Department of Materials Science, Tohoku University, Japan. 229 pp.

Bhattarai, J. 2000. The effect of immersion time in the corrosion rate and surface composition of the sputterdeposited W-22Ti and W-58Ti alloys. Journal of Nepal Chemical Society 19:32-41.

Bhattarai, J. 2001. Electrochemical and XPS studies on the corrosion behavior of sputter-deposited amorphous $\mathrm{W}-\mathrm{Ni}$ alloys in $12 \mathrm{M}$ HCl. Journal of Nepal Chemical Society 20:24-40.

Bhattarai, J. 2002. The anodic passivity of sputterdeposited W-Ti alloys in hydrochloric acid solutions. Nepal Journal of Science and Technology 4:37-43.

Bhattarai, J. 2006. Structure and corrosion behavior of sputter-deposited W-Mo alloys. Journal of Nepal Chemical Society 21:19-25.

Bhattarai, J., E. Akiyama, A. Kawashima, K. Asami and K. Hashimoto. 1995. The corrosion behavior of sputterdeposited amorphous $\mathrm{W}-\mathrm{Ti}$ alloys in $6 \mathrm{M} \mathrm{HCl}$ solution. Corrosion Science 37:2071-2086.

Bhattarai, J., E. Akiyama, H. Habazaki, A. Kawashima, K. Asami and K. Hashimoto. 1997. Electrochemical and XPS studies of the corrosion behavior of sputterdeposited amorphous $\mathrm{W}-\mathrm{Zr}$ alloys in 6 and $12 \mathrm{M} \mathrm{HCl}$ solutions. Corrosion Science 39:355-375.

Bhattarai, J., E. Akiyama, H. Habazaki, A. Kawashima, K. Asami and K. Hashimoto. 1998a. Electrochemical and XPS studies of the corrosion behavior of sputterdeposited amorphous $\mathrm{W}-\mathrm{Nb}$ alloys in concentrated hydrochloric acid solutions. Corrosion Science 40:19-42.

Bhattarai, J., E. Akiyama, H. Habazaki, A. Kawashima, K. Asami and K. Hashimoto. 1998b. Electrochemical and XPS studies of the passivation behavior of sputterdeposited $\mathrm{W}-\mathrm{Cr}$ alloys in $12 \mathrm{M} \mathrm{HCl}$ solution. Corrosion Science 40:155-175.

Bhattarai, J., E. Akiyama, H. Habazaki, A. Kawashima, K. Asami and K. Hashimoto. 1998c. The passivation behavior of sputter-deposited amorphous W-Ta alloys in $12 \mathrm{M} \mathrm{HCl}$ solution. Corrosion Science 40:757-779.

Bhattarai, J., E. Akiyama, H. Habazaki, A. Kawashima, K. Asami and K. Hashimoto. 1998d. The influence of concentration of hydrochloric acid solutions on the passivation behavior of sputter-deposited tungstenrich W-Nb alloys. Corrosion Science 40:1897-1914.

Bhattarai, J. and K. Hashimoto. 1998. X-ray photoelectron spectroscopy study in the anodic passivity of sputterdeposited nanocrystalline $\mathrm{W}-\mathrm{Cr}$ alloys in $12 \mathrm{M} \mathrm{HCl}$. Tribhuvan University Journal 21(2):1-16.

Bhattarai, J., A. Kawashima, K. Asami and K. Hashimoto. 1999. Roles of alloying elements in the extremely high 
Nepal Journal of Science and Technology 11 (2010) 147-152

corrosion resistance of sputter-deposited binary tungsten alloys in concentrated hydrochloric acids. Proc. $3^{\text {rd }}$ National Conference on Science and Technology, NAST, Kathmandu, Nepal 1:389-407.

Bhattarai, J. 2009. The effects of chromium and nickel on the passivation behavior of sputter-deposited W$\mathrm{Cr}-\mathrm{Ni}$ alloys in $12 \mathrm{M} \mathrm{HCl}$ solution. Scientific World 7:24-28.

Bhattarai, J. and A. B. Marahatta. 2010. The corrosion behavior of sputter-deposited nanocrystalline $\mathrm{W}-\mathrm{Mo}$ alloys in $0.5 \mathrm{M} \mathrm{NaCl}$ solution. Journal of Tribhuvan University Teacher's Association. Kirtipur Campus Unit 4/5: in press.

El-Moneim, A. A., B. P. Zhang, E. Akiyama, H. Habazaki, A. Kawashima, K. Asami and K. Hashimoto. 1997. The corrosion behavior of sputter-deposited amorphous $\mathrm{Mn}-\mathrm{Ti}$ alloys in $0.5 \mathrm{M} \mathrm{NaCl}$ solution. Corrosion Science 39:305-320.

El-Moneim, A. A., E. Akiyama, H. Habazaki, A. Kawashima, K. Asami and K. Hashimoto. 1999. Corrosion-resistant $\mathrm{Mn}-\mathrm{Zr}-\mathrm{Cr}$ alloys in chloridecontaining media. Materials Science and Engineering A267:285-293.

Hashimoto, K. 1993. Chemical properties of rapidly solidified alloys. In: Rapidly solidified alloys; processes, structures, properties and applications (Ed. Liebermann, H. H.), Marcel Dekker Inc., New York. pp. 591-615.

Hashimoto, K. 2007. The role of corrosion-resistant alloying elements in passivity. Corrosion Science 49:42-52.

Heusler, K. E. and D. Huerta. 1988. In : Proc. sym. corrosion, electrochemistry and catalysis of metallic glasses (Eds R. B. Diegle and K. Hashimoto). The Electrochem. Soc., Pennington, USA, p. 1.
Kim, J. H., E. Akiyama, H. Habazaki, A. Kawashima, K. Asami and K. Hashimoto. 1993. The corrosion behavior of sputter-deposited amorphous titanium-chromium alloys in $1 \mathrm{M}$ and $6 \mathrm{M} \mathrm{HCl}$ solutions. Corrosion Science 34:975-987.

Kim, J. H., E. Akiyama, H. Habazaki, A. Kawashima, K. Asami and K. Hashimoto. 1994. An XPS study of the corrosion behavior of sputter-deposited amorphous $\mathrm{Cr}-\mathrm{Nb}$ and $\mathrm{Cr}-\mathrm{Ta}$ alloys in $12 \mathrm{M} \mathrm{HCl}$ solution. Corrosion Science 36:511-523.

Li, X.-Y., E. Akiyama, H. Habazaki, A. Kawashima, K. Asami and K. Hashimoto. 1997. Spontaneously passivated films on sputter-deposited $\mathrm{Cr}-\mathrm{Ti}$ alloys in $6 \mathrm{M} \mathrm{HCl}$ solution. Corrosion Science 39:935948.

Park, P. Y., E. Akiyama, H. Habazaki, A. Kawashima, K. Asami and K. Hashimoto. 1994. The corrosion behavior of sputter-deposited amorphous $\mathrm{Cr}-\mathrm{Ni}-\mathrm{Mo}$ alloys in $12 \mathrm{M} \mathrm{HCl}$. Corrosion Science 36:1395-1410.

Park, P.Y., E. Akiyama, H. Habazaki, A. Kawashima, K. Asami and K. Hashimoto. 1995. The corrosion behavior of sputter-deposited amorphous $\mathrm{Mo}-\mathrm{Zr}$ alloys in $12 \mathrm{M} \mathrm{HCl}$. Corrosion Science 37: 307-320.

Park, P.Y., E. Akiyama, A. Kawashima, K. Asami and K. Hashimoto. 1996. The corrosion behavior of sputterdeposited Mo-Ta alloys in $12 \mathrm{M} \mathrm{HCl}$ solution. Corrosion Science 38:397-411.

Pourbaix, M. 1994. Atlas of electrochemical equilibrium in aqueous solution, NACE, Houston, TX, pp. 280-334.

Zarzycki, J. 1991. Materials Science and Technology: A Comprehensive Treatment (Eds R. W. Chan, P. Haasen \& E. J. Kramer). vol. 9, VCH Publishers Inc., New York. pp. 19. 